\title{
Risk Factors Associated with Mother-to-Child Transmission of HIV-1, Spontaneous Abortion and Infant Mortality in HIV-1 Infected Women in Burkina Faso: A Prospective Study
}

\author{
Serge Theophile Soubeiga ${ }^{1,2^{*}}$, Albert Theophane Yonli ${ }^{1,2}$, Tegwindé Rebeca Compaore ${ }^{1,2}$, \\ Abdoul Karim Ouattara, ${ }^{1,2}$, Birama Diarra ${ }^{1,2}$, Dorcas Obiri-Yeboah ${ }^{3}$, Zoenabo Douamba ${ }^{1,2}$, \\ Lassina Traore1,2, Wendkuuni Florencia Djigma1,2, Jacques Simpore ${ }^{1,2}$ \\ ${ }^{1}$ Pietro Annigoni Biomolecular Research Centre (CERBA), Ouagadougou, Burkina Faso \\ ${ }^{2}$ Laboratory of Molecular Biology and Genetics (LABIOGENE), University Ouaga I Prof. Joseph KI-ZERBO, \\ Ouagadougou, Burkina Faso \\ ${ }^{3}$ Department of Microbiology and Immunology, School of Medical Sciences, University of Cape Coast, Cape Coast, Ghana \\ Email: *s.soubeiga@labiogene.org
}

How to cite this paper: Soubeiga, S.T., Yonli, A.T., Compaore, T.R., Ouattara, A.K., Diarra, B., Obiri-Yeboah, D., Douamba, Z., Traore, L., Djigma, W.F. and Simpore, J. (2018) Risk Factors Associated with Mother-to-Child Transmission of HIV-1, Spontaneous Abortion and Infant Mortality in HIV-1 Infected Women in Burkina Faso: A Prospective Study. Journal of Biosciences and Medicines, 6, 12-21.

https://doi.org/10.4236/jbm.2018.610003

Received: August 16, 2018

Accepted: October 8, 2018

Published: October 11, 2018

Copyright (c) 2018 by authors and Scientific Research Publishing Inc. This work is licensed under the Creative Commons Attribution International License (CC BY 4.0).

http://creativecommons.org/licenses/by/4.0/

c) (i) Open Access

\begin{abstract}
Background: Despite efforts to fight, HIV/AIDS mother-to-child transmission of HIV-1 (MTCT), as well as abortion and infant mortality, remains a problem in sub-Saharan Africa. Indeed, a low level of CD4 and a high viral load can be associated with these situations. The aim of this study was to determine the risk factors associated with the occurrence of MTCT, spontaneous abortion and infant mortality in HIV-1 infected women in Ouagadougou, Burkina Faso. This was a prospective study conducted from May 2014 to September 2017 and involved 423 HIV-1 infected women followed at Saint Camille Hospital in Ouagadougou, Burkina Faso. Sociodemographic data were collected through a questionnaire. The CD4 count and HIV-1 viral load were determined using respectively BD FACSCount and Abbott m2000rt instruments. Bivariate analysis and multinomial logistic regression were performed for associations with a significance threshold for $\mathrm{p}<0.05$. Results: The average age of women was $38.75 \pm 7.98$ years. Rates of MTCT, abortion and infant mortality were $16.31 \%, 30.49 \%$ and $34.75 \%$, respectively. The number of pregnancies was associated with the number of infant deaths $(\mathrm{p}=$ 0.002 ). A correlation between the number of pregnancies and infant mortality was observed $(\mathrm{p}=0.002)$ with a relatively high rate $(28.6 \%)$ among women who had three pregnancies. In addition, marital status was associated with HIV-1 infection in infants $(\mathrm{p}=0.042)$ and spontaneous abortion $(\mathrm{p}=0.033)$. HIV-1 infected women with low CD4 counts (less than 350 cells $/ \mu \mathrm{L}$ ) and
\end{abstract}


those with viral load more than 1000 copies/mL were about twice as likely to have an spontaneous abortion [OR (IC 95\%): 2.50 (1.085 - 5.760); $\mathrm{p}=0.03$ ] and [OR (95\% CI): 2.16 (1.043 - 4.505); $\mathrm{p}=0.04$ ]. Conclusions: The results of this study show the need to improve the treatment of HIV-1 infected women in order to restore CD4 levels and make viral load of HIV-1 undetectable.

\section{Keywords}

HIV-1, MTCT, Abortion, Infants, Burkina Faso

\section{Introduction}

Human immunodeficiency virus type 1 (HIV-1) continues to affect many people worldwide despite prevention and antiretroviral therapy (ART). In 2016, 36.7 million (30.8 million - 42.9 million) people was living with HIV/AIDS [1] in the world. In the same year, the number of women (15 years and older) and children ( $<15$ years) infected with HIV-1 was estimated at 17.8 million (15.4 million 20.3 million) and 2.1 million (1.7 million - 2.6 million) respectively [1].

In Burkina Faso, the rate of adherence of pregnant women to the prevention of mother-to-child transmission of HIV-1 (PMTCT) was $86.14 \%$ in 2015, still below the national target of $90 \%$. In addition, the residual rate of MTCT decreased from $5.30 \%$ in 2014 to $4.95 \%$ in 2015 [2]. The MTCT of HIV-1 is always real because most of serodiscordant couples or those living with HIV-1 are sexually active and express the desire to have children [3] [4]. A combination of ARVs, elective cesarean, and abstinence from breastfeeding can significantly reduce MTCT [5]. When the HIV status of the pregnant woman is known, midwives can take precautions to avoid possible complications that may lead to transmission of the virus to the baby during delivery. Despite these preventive measures, some children may be infected either during pregnancy, childbirth or breastfeeding [6] [7] [8]. Several studies have shown that age, undetectable viral load, and high CD4 T-cell counts were associated with reproductive desire in couples living with HIV-1 [9] [10]. It should be noted that there are cases of spontaneous abortions and stillbirths due to complications that can be caused by HIV-1 infection [11] [12].

However, other studies have found that high viral load is a high risk factor for the loss of the baby in HIV-1 infected pregnant women [13]. In Burkina Faso, no study has yet been conducted about the association of risk factors related to desire for children, MTCT and infant mortality. Therefore, the objective of this study was to identify the risk factors for these complications in order to strengthen the prevention and treatment strategies in HIV-1 infected pregnant women and their children in Burkina Faso.

\section{Material and Methods}

\section{1) Type and period of study}


It was a prospective study that took place from May 2014 to September 2017 at Saint Camille Hospital in Ouagadougou, Burkina Faso.

\section{2) Study population}

This study involved a cohort of 423 HIV-1 infected women followed at Saint Camille Hospital in Ouagadougou as part of the PMTCT strategy. Patients are selected according to HIV-1 status and availability of sociodemographic and clinical data. Data such as age, profession, marital status, number of infants HIV-1 positive, number of spontaneous abortions, number of children who died, and adherence to ART were collected through a questionnaire.

\section{3) Determination of CD4 T cell count and HIV-1 plasma viral load}

Whole blood samples were taken in two EDTA tubes. The first tube was used for determination of $\mathrm{CD} 4 \mathrm{~T}$ cell count using BD FACSCount (BD Dickinson, CA, USA) while the second tube was centrifuged at $5000 \mathrm{rpm}$ for 5 minutes, to collect plasma that was used to quantify the HIV-1 plasma viral load on the Abbott m2000rt instrument (Abbott Laboratories, USA) according manufacturer's instructions.

\section{4) Statistical data analysis}

The data was analyzed using IBM SPSS software version 21.0. The Chi square test was used for comparisons. Bivariate analysis and multinomial logistic regression were used for the associations. The difference was considered statistically significant for $\mathrm{p}<0.05$.

\section{5) Ethical considerations}

This study has been approved by the Ethics Committee for Health Research in Burkina Faso (deliberation $N^{\circ}$ 2014-7-084). All participants gave their free and informed consent. Anonymity and confidentiality have been respected.

\section{Results}

\section{1) Sociodemographic and biological characteristics}

In this study, the age of women was between 19 to 64 years with a mean age of $38.75 \pm 7.98$ years. Of them, $68.1 \%(288 / 423)$ were married and $52.5 \%(222 / 423)$ were illiterate.

The mean CD4 count was $449.98 \pm 240.98$ cell $/ \mu \mathrm{L}$. In this study, $40.4 \%$ of women had a CD4 count less than 350 cell/ $\mu \mathrm{L}$ while $44.7 \%$ had a plasma viral load more than 1000 copies/mL.

\section{2) Rates of MTCT, spontaneous abortion and death of children}

This study reported a mother-to-child transmission rate of $16.31 \%(69 / 423)$. The rate of spontaneous abortion and child mortality were $30.49 \%(129 / 423)$ and $34.75 \%$ (147/423) respectively.

3) MTCT, number of spontaneous abortions and number of deceased children according to sociodemographic parameters

Analysis of the results showed a significant difference between the number of pregnancies and the number of spontaneous abortions $(\mathrm{p}<0.001)$. Women who had 4, 5 or 6 pregnancies had at least 2 spontaneous abortions. An association 
between the number of pregnancies and the number of deceased children ( $\mathrm{p}=$ 0.002 ) was also found. In fact, women who had 3 pregnancies recorded the most infant mortality (28.6\%) (Table 1). There was also an association between the marital status of women and the number of children borned HIV-1 positive ( $\mathrm{p}=$ $0.042)$ and the number of spontaneous abortions $(p=0.033)$. Married women had the highest number of children borned HIV-1 positive $(52.2 \%)$ and the highest number of spontaneous abortions (53.5\%). There was no statistically significant difference between the occupation of women and the number of children infected with HIV-1, the number of spontaneous abortions and the number of deceased children. But the illiterate women had the most HIV-1 infected children, the most spontaneous abortion and the most deceased children. Also, there was no association between the age of women and MTCT, spontaneous abortion and infant mortality (Table 1).

Table 1. Bivariate analysis of sociodemographic parameters with number of children borned HIV-1 (+), spontaneous abortion and children dead.

\begin{tabular}{|c|c|c|c|c|c|c|c|c|c|c|c|c|c|c|}
\hline & \multicolumn{2}{|c|}{$\begin{array}{c}\text { Number of } \\
\text { children borned } \\
\text { HIV-1(+) }\end{array}$} & \multirow[t]{2}{*}{$\begin{array}{c}\text { Total } \\
(\mathrm{n}=69)\end{array}$} & \multirow[t]{2}{*}{ p-value } & \multicolumn{3}{|c|}{$\begin{array}{l}\text { Number of spontaneous } \\
\text { abortions }\end{array}$} & \multirow[t]{2}{*}{$\begin{array}{c}\text { Total } \\
(n=129)\end{array}$} & \multirow[t]{2}{*}{ p-value } & \multicolumn{3}{|c|}{ Number of children dead } & \multirow[t]{2}{*}{$\begin{array}{c}\text { Total } \\
(\mathrm{n}=147)\end{array}$} & \multirow[t]{2}{*}{ p-value } \\
\hline & 1 & 2 & & & 1 & 2 & 3 & & & 1 & 2 & 3 & & \\
\hline \multicolumn{15}{|c|}{ Age (years) } \\
\hline $20-30$ & $15(21.7)$ & $0(0.0)$ & $15(21.7)$ & & $15(11.6)$ & $0(0.0)$ & $3(2.3)$ & $18(13.9)$ & & $12(8.2)$ & $0(0.0)$ & $0(0.0)$ & $12(8.2)$ & \\
\hline $31-40$ & $27(39.1)$ & $3(4.3)$ & $30(43.4)$ & & $48(37.2)$ & $0(0.0)$ & $6(4.6)$ & $48(41.8)$ & & $42(28.6)$ & $39(26.5)$ & $3(2.0)$ & $84(57.1)$ & \\
\hline $41-50$ & $12(17.4)$ & $9(13.0)$ & $21(30.4)$ & 0.172 & $36(27.9)$ & $6(4.6)$ & $0(0.0)$ & $42(32.5)$ & 0.295 & $9(6.1)$ & $24(16.4)$ & $3(2.0)$ & $36(24.5)$ & 0.509 \\
\hline$>50$ & $3(4.3)$ & $0(13.0)$ & $3(4.3)$ & & $12(9.3)$ & $0(0.0)$ & $3(2.3)$ & $15(11.6)$ & & $9(6.1)$ & $6(4.1)$ & $0(0.0)$ & $15(10.2)$ & \\
\hline Total & $57(82.6)$ & $12(17.4)$ & $69(100)$ & & $111(86.0)$ & $6(4.6)$ & $12(9.2)$ & $129(100)$ & & $72(49.0)$ & $69(47.0)$ & $6(4.0)$ & $147(100)$ & \\
\hline \multicolumn{15}{|c|}{ Number of pregnancies* } \\
\hline 1 & $21(33.3)$ & $0(0.0)$ & $21(33.3)$ & & $6(4.7)$ & $0(0.0)$ & $0(0.0)$ & $6(4.7)$ & & $24(16.3)$ & $3(2.0)$ & $0(0.0)$ & $27(18.3)$ & \\
\hline 2 & $6(9.5)$ & $3(4.8)$ & $9(14.3)$ & & $18(14.0)$ & $0(0.0)$ & $0(0.0)$ & $18(14.0)$ & & $18(12.2)$ & $24(16.3)$ & $0(0.0)$ & $42(28.5)$ & \\
\hline 3 & $15(23.8)$ & $6(9.5)$ & $21(33.3)$ & & $57(44.2)$ & $0(0.0)$ & $0(0.0)$ & $57(44.2)$ & & $12(8.2)$ & $42(28.6)$ & $3(2.0)$ & $57(38.8)$ & \\
\hline 4 & $9(14.3)$ & $0(0.0)$ & $9(14.3)$ & 0.642 & 24 (18.6) & $0(0.0)$ & $3(2.3)$ & $27(20.9)$ & $<0.001$ & $15(10.2)$ & $0(0.0)$ & $0(0.0)$ & $15(10.2)$ & 0.002 \\
\hline 5 & $3(4.8)$ & $0(0.0)$ & $3(4.8)$ & & $6(4.7)$ & $6(4.7)$ & $6(4.7)$ & $18(14.0)$ & & $0(0.0)$ & $0(0.0)$ & $3(2.0)$ & $3(2.0)$ & \\
\hline 6 & $0(0.0)$ & $0(0.0)$ & $0(0.0)$ & & $0(0.0)$ & $0(0.0)$ & $3(2.3)$ & $3(2.3)$ & & $0(0.0)$ & $3(2.0)$ & $0(2.0)$ & $3(2.0)$ & \\
\hline Total & $54(85.7$ & $27(14.3)$ & $63(100)$ & & $111(86.0)$ & $6(4.6)$ & $12(9.2)$ & $129(100)$ & & $69(49.0)$ & $72(47.0)$ & $6(4.0)$ & $147(100)$ & \\
\hline \multicolumn{15}{|c|}{ Education } \\
\hline Illiterate & $30(43.5)$ & $3(4.3)$ & $33(47.8)$ & & $61(48.8)$ & $6(4.6)$ & $9(7.0)$ & $78(60.5)$ & & $33(22.4)$ & $36(24.5)$ & $6(4.1)$ & $75(51.0)$ & \\
\hline Primary & $12(17.4)$ & $3(4.3)$ & $15(21.7)$ & & $39(30.2)$ & $0(0.0)$ & $3(2.3)$ & $42(32.5)$ & & $21(14.3)$ & $15(10.2)$ & $0(0.0)$ & $36(24.5)$ & \\
\hline Secondary & $9(13.0)$ & $0(0.0)$ & $9(13.0)$ & 0.149 & $6(4.6)$ & $0(0.0)$ & $0(0.0)$ & $6(4.6)$ & 0.481 & $3(2.0)$ & $9(6.1)$ & $0(0.0)$ & $12(8.1)$ & 0.480 \\
\hline University & $6(8.7)$ & $6(8.7)$ & $12(17.4)$ & & $3(2.3)$ & $0(0.0)$ & $0(0.0)$ & $3(2.3)$ & & $15(10.2)$ & $9(6.1)$ & $0(0.0)$ & $24(16.1)$ & \\
\hline Total & $57(82.6)$ & $12(17.4)$ & $69(100)$ & & $111(86.0)$ & $6(4.6)$ & $12(9.2)$ & $129(100)$ & & $72(49.0)$ & $69(47.0)$ & $6(4.0)$ & $147(100)$ & \\
\hline \multicolumn{15}{|c|}{ Marital status } \\
\hline
\end{tabular}




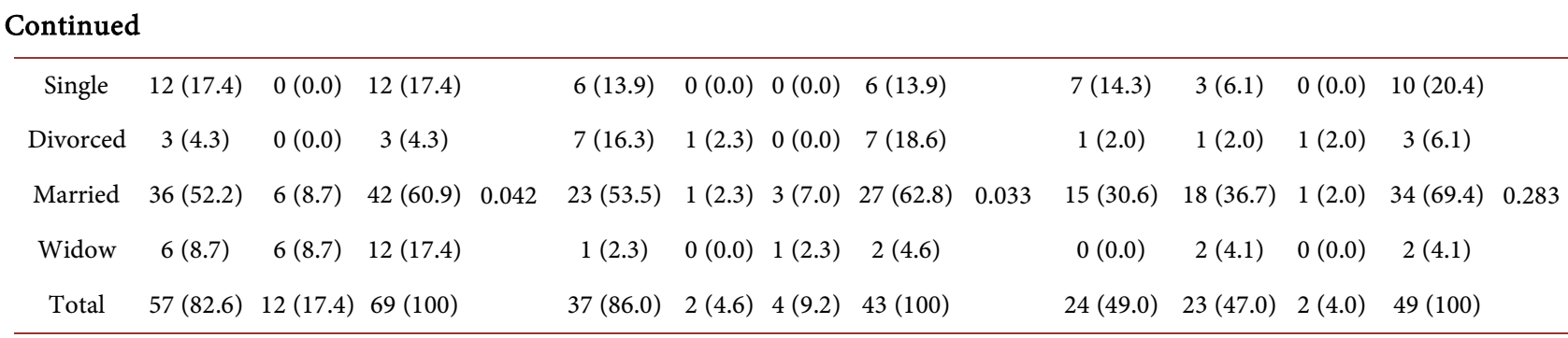

${ }^{*}$ The total number of children borned HIV-1(+) in relation to the number of pregnancies is 21 because the cases of absence of pregnancy ( 0 pregnancy) thus 0 child HIV-1(+), 0 spontaneous abortion and 0 death could not be considered in the table.

\section{4) Risk factors associated with MTCT, spontaneous abortion and children dead}

Multinomial logistic regression revealed that women with low CD4 $\mathrm{T}$ cell counts $(<350$ cells $/ \mu \mathrm{L})$ were statistically twice as likely to have a spontaneous abortion [OR (95\% CI): 2.50 (1.085 - 5.760); p = 0.03]. Similarly, those with a viral load more than 1000 copies/mL were twice as likely to have a spontaneous abortion [OR (95\% CI): 2.16 (1.043 - 4.505); p = 0.04] (Table 2). At the level of education, illiterate women were fourteen times more likely to transmit HIV-1 infection to their baby [(OR (95\% CI): 14.00 (1.149 - 179.555), $\mathrm{p}=0.039$ ]. Married women were about eleven times more likely to have a spontaneous abortion (OR (95\% CI: 10.7 (1.387 - 82.033), p = 0.023) (Table 2). In this study, no risk has been associated with the mortality of children born from HIV-1 infected mothers. This study showed no risk for MTCT, spontaneous abortion and infant mortality with the age of women.

\section{Discussion}

This study, conducted for the first time in Burkina Faso, showed a high rate of MTCT of $16.31 \%$. This rate was significantly higher than the national rate of $4.95 \%$ reported in 2015 [2]. It also reported a spontaneous abortion rate of $30.49 \%$ and $34.75 \%$ of infant mortality rate for infant born from HIV-1 infected mothers. In addition, the number of spontaneous abortions was significantly associated with the number of pregnancies. Indeed, the study showed that women who had at least four pregnancies had more than two spontaneous abortions. This means that as the number of pregnancies increases, the risk of spontaneous abortion is high. The high number of pregnancies is explained by the strong desire for reproduction in HIV-1 infected women [10]. A significant relationship was also found between marital status and number of abortions and number of children deceased. The rate of MTCT was higher among married women (52.2\%) as well as the number of abortions ( 3 cases of abortions). Marriage and the high number of pregnancies are factors that express an active sex life and thus reflect a strong desire for children among HIV-1 infected couples. In Burkina Faso, a demographic and health survey conducted in 2010 showed that the desire for children is quite high among women in general, including HIV-1 infected women [14]. The spontaneous abortion rate found in our study is very high, even 
Table 2. Multinomial logistic regression of factors associated with MTCT, spontaneous abortion and infant mortality in relation to the sociodemographic characteristics of the study population.

\begin{tabular}{|c|c|c|c|c|c|c|c|c|c|}
\hline \multirow[t]{2}{*}{ Characteristics } & \multicolumn{3}{|c|}{ MTCT $(n=69)$} & \multicolumn{3}{|c|}{ Spontaneous abortion $(n=129)$} & \multicolumn{3}{|c|}{ Infant mortality $(n=147)$} \\
\hline & n (\%) & OR (CI 95\%) & $\mathrm{p}$-value & $\mathrm{n}(\%)$ & OR (CI 95\%) & p-value & n (\%) & OR (CI 95\%) & $\mathrm{p}$-value \\
\hline \multicolumn{10}{|c|}{ Age (years) } \\
\hline $20-30$ & $15(21.7)$ & $0.2(0.020-1.956)$ & 0.167 & $18(13.9)$ & $0.90(0.207-3.907)$ & 0.88 & $12(8.2)$ & $1.94(0.409-9.242)$ & 0.40 \\
\hline $31-40$ & $30(43.4)$ & $0.47(0.056-4.057)$ & 0.498 & $54(41.8)$ & $0.60(0.178-2.025)$ & 0.41 & $84(57.1)$ & $0.87(0.265-2.874)$ & 0.82 \\
\hline $41-50$ & $21(30.4)$ & $0.33(0.037-2.985)$ & 0.322 & $42(32.5)$ & $1.09(0.305-3.938)$ & 0.90 & $36(24.5)$ & $1.03(0.284-3.707)$ & 0.97 \\
\hline$>50$ & $3(4.3)$ & - & - & $15(11.6)$ & - & - & $15(10.2)$ & - & - \\
\hline \multicolumn{10}{|c|}{ Number of pregnancies* } \\
\hline 1 & $21(33.3)$ & - & - & $6(4.7)$ & $0.07(0.003-1.747)$ & 0.11 & $27(18.3)$ & $0.08(0.003-2.603)$ & 0.16 \\
\hline 2 & $9(14.3)$ & - & - & $54(14.0)$ & $0.2(0.011-3.661)$ & 0.28 & $42(28.5)$ & $0.47(0.027-8.464)$ & 0.61 \\
\hline 3 & $21(33.3)$ & - & - & $57(44.2)$ & $0.79(0.046-13.501)$ & 0.87 & $57(38.8)$ & $0.64(0.037-11.020)$ & 0.76 \\
\hline 4 & $9(14.3)$ & - & - & $27(20.9)$ & $2.25(0.111-45.723)$ & 0.60 & $15(10.2)$ & $0.79(0.046-13.50)$ & 0.87 \\
\hline 5 & $3(4.8)$ & - & - & $18(14.0)$ & - & - & $3(2.0)$ & $0.62(0.031-12.410)$ & 0.76 \\
\hline 6 & $0(0.0)$ & - & - & $3(2.3)$ & - & - & $3(2.0)$ & - & - \\
\hline \multicolumn{10}{|c|}{ CD4 (cells $/ \mu \mathrm{L})$} \\
\hline$<350$ & $30(43.5 \%)$ & $1.25(0.454-3.445)$ & 0.66 & $30(23.3)$ & $2.50(1.085-5.760)$ & 0.03 & $60(40.8)$ & $0.87(0.408-1.875)$ & 0.73 \\
\hline $350-500$ & $15(21.7 \%)$ & $1.22(0.361-4.149)$ & 0.74 & $33(25.6)$ & $1.48(0.571-3.846)$ & 0.42 & $21(14.3)$ & $0.48(0.174-1.307)$ & 0.15 \\
\hline$>500$ & $24(34.8 \%)$ & - & - & $66(51.2)$ & - & - & $66(44.9)$ & - & - \\
\hline \multicolumn{10}{|c|}{ VIH-1 viral load (copies/mL) } \\
\hline$>1000$ & $30(43.5 \%)$ & $1.13(0.461-2.760)$ & 0.79 & $12(9.3)$ & $2.16(1.043-4.505)$ & 0.04 & $12(8.2)$ & $1.02(0.513-2.038)$ & 0.95 \\
\hline \multicolumn{10}{|c|}{ Education } \\
\hline Illiterate & $33(47.8)$ & $14.00(1.149-179.555)$ & 0.039 & $78(60.5)$ & $6.5(0.800-52.820)$ & 0.080 & $75(51.0)$ & $0.32(0.094-1.077)$ & 0.06 \\
\hline Primary & $15(21.7)$ & $7.556(0.614-93.006)$ & 0.114 & $42(32.5)$ & $6.6(0.789-57.250)$ & 0.081 & $36(24.5)$ & $0.31(0.085-1.147)$ & 0.08 \\
\hline Secondary & $9(13.0)$ & - & - & $6(4.6)$ & $1.8(0.148-23.070)$ & 0.634 & $12(8.1)$ & $0.23(0.046-1.125)$ & 0.69 \\
\hline University & $12(17.4)$ & - & - & $3(2.3)$ & - & - & $24(16.1)$ & - & - \\
\hline \multicolumn{10}{|c|}{ Marital Status } \\
\hline Single & $12(17.4)$ & $3.3(0.634-17.518)$ & 0.155 & $6(13.9)$ & $1.3(0.220-8.099)$ & 0.755 & $10(20.4)$ & $2.8(0.497-16.427)$ & 0.239 \\
\hline Married & $3(4.3)$ & $6.6(0.597-74.504)$ & 0.123 & $7(18.6)$ & $10.7(1.387-82.033)$ & 0.023 & $3(6.1)$ & $1.5(0.195-11.536)$ & 0.697 \\
\hline Divorced & $42(60.9)$ & $3.9(0.976-15.619)$ & 0.054 & $27(62.8)$ & $1.6(0.312-7.847)$ & 0.586 & $34(69.4)$ & $2.29(0.461-11.416)$ & 0.310 \\
\hline Widow & $12(17.4)$ & - & - & $2(4.6)$ & - & - & $2(4.1)$ & - & - \\
\hline
\end{tabular}

OR $=$ Odds ratio, CI $95 \%=$ Confidence interval to $95 \%$.

though these women are on highly active antiretroviral therapy (HAART). Indeed, some authors have reported that miscarriages, ectopic pregnancies and stillbirths are common among HIV-infected women (some of whom are on ART) compared to HIV-1-negative women [15] [16]. This is supported by other authors who have shown that HIV-1 infection in women is associated with an increased risk of adverse birth outcomes, even if they are on ART [17] [18] [19]. It 
should be noted that most HIV-infected women have been infected during their youth because of their active sex life and may have an unwanted pregnancy and decide to end it [20]. Studies have shown that HIV-1 infected pregnant women were four times more likely to lose their pregnancies than those who were not infected [21]. In this study, married women were about eleven times more likely to have a spontaneous abortion and had the highest number of spontaneous abortions. This could be explained by factors such as psychological weight when they are declared HIV-1 positive during pregnancy, discrimination, fear of giving birth to an infected child and lack of support from the husband. Moreover, our results showed that HIV-1 infected women with low CD4 counts $(<350$ cells $/ \mu \mathrm{L}$ ) and a viral load more than 1000 copies/mL are twice as likely to have a spontaneous abortion. Indeed, these two factors can influence the course of pregnancy. In Brazil, a study showed that the risks of complications was very high for the mother and the foetus, when the mother develops an opportunistic disease related to HIV-1 and when the CD4 T lymphocyte counts are less than $200 \mathrm{cell} / \mu \mathrm{L}$ [22]. A higher plasma viral load is a marker of disease severity in the mother, and has been associated with adverse birth outcomes [13] [19] [23]. That is why it is important to achieve the third objective 90 of UNAIDS in 2020 about the suppression of viral load because this will avoid certain risks of complications during pregnancy such as spontaneous abortion. The illiterate women in our study were about 14 times more likely to transmit HIV-1 infection to their baby. This could be explained by ignorance of ways of PMTCT and contraceptive methods. Our study showed a correlation between the number of pregnancies and the occurrence of death of children born from HIV-1 infected mothers. Indeed, those who had 3 pregnancies had the most two deaths of children. We did not find an association between the number of infant who died with age, the CD4 $\mathrm{T}$ cell count, and the viral load of mothers. In contrast, in the United States, one study reported that age, CD4 T-cell count, race/ethnicity of HIV-1-infected mothers were associated with childhood death [24]. In the same study, some children died from opportunistic infections (cytomegalovirus, liver disease, pneumonia, sepsis). But, it is important to note that since 2010, there has been a 33\% decrease in new HIV-1 infections among children in West and Central Africa [1]. It can be expected that the recent ART guidelines of WHO, which recommend treatment for all HIV-infected persons, will be an important structural intervention for the elimination of mother-to-child transmission, and therefore zero HIV-1 infected children and zero death [25].

One of the limitations of our study is that we could not have information on whether or not the deceased children were on treatment, whether they had opportunistic infections or not, their age at death, which could have allowed us to deepen our analysis. Also, all women were on ART and most of them had good compliance.

\section{Conclusion}

This study identified risk factors associated with MTCT, spontaneous abortion 
and infant mortality. It showed that the number of pregnancies among women was associated with both spontaneous abortion and infant mortality. Marital status was associated with MTCT and child deaths. This study also showed that low CD4 T cell counts and high viral load as well as marital status are high risk factors for abortion. Similarly, lack of education was a high risk factor for MTCT. It is therefore important to strengthen information and awareness about PMTCT and improve the treatment of HIV-1 infected women in Burkina Faso.

\section{Acknowledgements}

The authors wish to thank Saint Camille Hospital, CERBA/LABIOGENE and express their gratitude to the Italian Episcopal Conference (CEI) and the West African Economic and Monetary Union (WAEMU) (through the PACER2 program).

\section{Conflicts of Interest}

The authors declare no conflicts of interest regarding the publication of this paper.

\section{References}

[1] UNAIDS (2017) Fiche d'information-Journée mondiale de lutte contre le SIDA. http://www.unaids.org/fr/resources/campaigns/right-to-health

[2] CNLST (2016) Rapport d'activité sur la riposte au SIDA au Burkina Faso. http://www.unaids.org/en/file/110917/download?token=6aVHZQzY

[3] Nobrega, A.A., Oliveira, F.A., Galvao, M.T., Mota, R.S., Barbosa, R.M., Dourado, I., Kendall, C. and Kerr-Pontes, L.R. (2007) Desire for a Child among Women Living with HIV/AIDS in Northeast Brazil. AIDS Patient Care STDS, 21, 261-267. https://doi.org/10.1089/apc.2006.0116

[4] Kawale, P., Mindry, D., Stramotas, S., Chilikoh, P., Phoya, A., Henry, K., Elashoff, D., Jansen, P. and Hoffman, R. (2014) Factors Associated with Desire for Children among HIV-Infected Women and Men: A Quantitative and Qualitative Analysis from Malawi and Implications for the Delivery of Safer Conception Counseling. AIDS Care, 26, 769-776. https://doi.org/10.1080/09540121.2013.855294

[5] Abtew, S., Awoke, W. and Asrat, A. (2016) Knowledge of Pregnant Women on Mother-to-Child Transmission of HIV, Its Prevention, and Associated Factors in Assosa Town, Northwest Ethiopia. HIV AIDS, 8, 101-107. https://doi.org/10.2147/HIV.S100301

[6] Simpore, J., Pietra, V., Pignatelli, S., Karou, D., Nadembega, W.M., Ilboudo, D., Ceccherini-Silberstein, F., Ghilat-Avoid-Belem, W.N., Bellocchi, M.C., Saleri, N., Sanou, M.J., Ouedraogo, C.M., Nikiema, J.B., Colizzi, V., Perno, C.P., Castelli, F. and Musumeci, S. (2007) Effective Program against Mother-to-Child Transmission of HIV at Saint Camille Medical Centre in Burkina Faso. Journal of Medical Virology, 79, 873-879. https://doi.org/10.1002/jmv.20913

[7] Sagna, T., Bisseye, C., Compaore, T.R., Kagone, T.S., Djigma, F.W., Ouermi, D., Pirkle, C.M., Zeba, M.T., Bazie, V.J., Douamba, Z., Moret, R., Pietra, V., Koama, A., Gnoula, C., Sia, J.D., Nikiema, J.B. and Simpore, J. (2015) Prevention of Mother-to-Child HIV-1 Transmission in Burkina Faso: Evaluation of Vertical Transmission by PCR, Molecular Characterization of Subtypes and Determination of Antire- 
troviral Drugs Resistance. Global Health Action, 8, Article ID: 26065.

https://doi.org/10.3402/gha.v8.26065

[8] Soubeiga, S.T., Compaore, R., Djigma, F., Zagre, N., Assengone, E., Traore, L., Diarra, B., Bisseye, C., Ouermi, D., Sagna, T., Karou, S., Pietra, V. and Simpore, J. (2015) Evaluation of Antiretroviral Therapy on Mother to Child Transmission HIV in HIV-1 Positive Pregnant Women: Case of St. Camillus Medical Center in Ouagadougou, Burkina Faso. Pan African Medical Journal, 20, 399.

[9] Mmbaga, E.J., Leyna, G.H., Ezekiel, M.J. and Kakoko, D.C. (2013) Fertility Desire and Intention of People Living with HIV/AIDS in Tanzania: A Call for Restructuring Care and Treatment Services. BMC Public Health, 13, 86.

https://doi.org/10.1186/1471-2458-13-86

[10] De Souza, M.R., do Amaral, W.N., Guimarães, R.A., Rezza, G. and Brunini, S.M. (2017) Reproductive Desire among Women Living with HIV/AIDS in Central Brazil: Prevalence and Associated Factors. PLoS One, 12, e0186267.

https://doi.org/10.1371/journal.pone.0186267

[11] Okong, P., Biryahwaho, B. and Bergstrom, S. (2002) Post-Abortion Endometritis-Myometritis and HIV Infection. International Journal of STD \& AIDS, 13, 729-732. https://doi.org/10.1258/095646202320753664

[12] Cates, J.E., Westreich, D., Edmonds, A., Wright, R.L., Minkoff, H., Colie, C., Greenblatt, R.M., Cejtin, H.E., Karim, R., Haddad, L.B., Kempf, M.C., Golub, E.T. and Adimora, A.A. (2015) The Effects of Viral Load Burden on Pregnancy Loss among HIV-Infected Women in the United States. Infectious Diseases in Obstetrics and Gynecology, 2015, Article ID: 362357. https://doi.org/10.1155/2015/362357

[13] Kim, H.Y., Kasonde, P., Mwiya, M., Thea, D.M., Kankasa, C., Sinkala, M., Aldrovandi, G. and Kuhn, L. (2012) Pregnancy Loss and Role of Infant HIV Status on Perinatal Mortality among HIV-Infected Women. BMC Pediatrics, 12, 138. https://doi.org/10.1186/1471-2431-12-138

[14] EDSBF-MICSIV (2010) Enquête Démographique et de Santé (EDS-IV) et à Indicateurs Multiples. https://www.unicef.org/bfa/french/bf_eds_2010.pdf

[15] Bussmann, H., Wester, C.W., Wester, C.N., Lekoko, B., Okezie, O., Thomas, A.M., DeGruttola, S.M., Makhema, J., Essex, M. and Marlink, R.G. (2007) Pregnancy Rates and Birth Outcomes among Women on Efavirenz-Containing Highly Active Antiretroviral Therapy in Botswana. Journal of Acquired Immune Deficiency Syndromes, 45, 269-273.

[16] Kolte, L., Gaardbo, J.C., Karlsson, I., Sorensen, A.L., Ryder, L.P., Skogstrand, K., Ladelund, S. and Nielsen, S.D. (2011) Dysregulation of CD4+ CD25+ CD127lowFOXP3+ Regulatory T Cells in HIV-Infected Pregnant Women. Blood, 117, 1861-1868. https://doi.org/10.1182/blood-2010-07-298992

[17] Schwartz, S.R., Rees, H., Mehta, S., Venter, W.D., Taha, T.E. and Black, V. (2012) High Incidence of Unplanned Pregnancy after Antiretroviral Therapy Initiation: Findings from a Prospective Cohort Study in South Africa. PLoS ONE, 7, e36039. https://doi.org/10.1371/journal.pone.0036039

[18] Chen, J.Y., Ribaudo, H.J., Souda, S., Parekh, N., Ogwu, A., Lockman, S., Powis, K., Dryden-Peterson, S., Creek, T., Jimbo, W., Madidimalo, T., Makhema, J., Essex, M. and Shapiro, R.L. (2012) Highly Active Antiretroviral Therapy and Adverse Birth Outcomes among HIV-Infected Women in Botswana. The Journal of Infectious Diseases, 206, 1695-1705. https://doi.org/10.1093/infdis/jis553

[19] Ezechi, O.C., Gab-Okafor, C.V., Oladele, D.A., Kalejaiye, O.O., Oke, B.O., Ohwodo, H.O., Adu, R.A., Ekama, S.O., Musa, Z., Onwujekwe, D.I., David, A.N. and Ujah, 
I.A. (2013) Pregnancy, Obstetric and Neonatal Outcomes in HIV Positive Nigerian Women. African Journal of Reproductive Health, 17, 160-168.

[20] Barbosa, R.M., Pinho, A.A., Santos, N.S. and Villela, W.V. (2012) Exploring the Relationship between Induced Abortion and HIV Infection in Brazil. Reprod Health Matters, 20, 80-89. https://doi.org/10.1016/S0968-8080(12)39633-X

[21] Brocklehurst, P. and French, R. (1998) The Association between Maternal HIV Infection and Perinatal Outcome: A Systematic Review of the Literature and $\mathrm{Me}$ ta-Analysis. British Journal of Obstetrics and Gynaecology, 105, 836-848. https://doi.org/10.1111/j.1471-0528.1998.tb10227.x

[22] El Beitune, P., Duarte, G., Quintana, S.M., Figueiro-Filho, E.A., Marcolin, A.C. and Abduch, R. (2004) Antiretroviral Therapy during Pregnancy and Early Neonatal Life: Consequences for HIV-Exposed, Uninfected Children. The Journal of Infectious Diseases, 8, 140-150. https://doi.org/10.1590/S1413-86702004000200004

[23] Turner, A.N., Tabbah, S., Mwapasa, V., Rogerson, S.J., Meshnick, S.R., Ackerman, W.E. and Kwiek, J.J. (2013) Severity of Maternal HIV-1 Disease Is Associated with Adverse Birth Outcomes in Malawian Women: A Cohort Study. Journal of Acquired Immune Deficiency Syndromes, 64, 392-399. https://doi.org/10.1097/QAI.0b013e3182a2d13c

[24] Brady, M.T., Oleske, J.M., Williams, P.L., Elgie, C., Mofenson, L.M., Dankner, W.M., Van Dyke, R.B. and Pediatric, A.C.T.G.C.T. (2010) Declines in Mortality Rates and Changes in Causes of Death in HIV-1-Infected Children during the HAART Era. Journal of Acquired Immune Deficiency Syndromes, 53, 86-94. https://doi.org/10.1097/QAI.0b013e3181b9869f

[25] Nesheim, S., Harris, L.F. and Lampe, M. (2013) Elimination of Perinatal HIV Infection in the United States and Other High-Income Countries: Achievements and Challenges. Current Opinion in HIV and AIDS, 8, 447-456.

https://doi.org/10.1097/COH.0b013e3283636ccb

\section{List of Abbreviations}

AIDS: Acquired immunodeficiency diseases syndrome;

ART: Antiretroviral therapy;

HAART: Highly active antiretroviral treatment,

HIV-1: Human immunodeficiency virus type 1;

CI: Confidence interval;

PMTCT: Prevention of mother-to-child transmission;

OR: Odds ratio. 